\title{
Efficiency of diagnostic biomarkers among colonic schistosomiasis Egyptian patients
}

\author{
Manal Abdel Aziz Hamed ${ }^{1 /+}$, Samia Abdel Aziz Ahmed ${ }^{1}$, Hussein Moustafa Khaled ${ }^{2}$ \\ ${ }^{1}$ Therapeutic Chemistry Department, National Research Center, Dokki, Cairo, Egypt \\ ${ }^{2}$ Department of Medical Oncology, National Cancer Institute, Cairo University, Cairo, Egypt
}

The schistosomal parasite plays a critical role in the development of malignant lesions in different organs. The pathogenesis of cancer is currently under intense investigation to identify reliable prognostic indices for disease detection. The objective of this paper is to evaluate certain biochemical parameters as diagnostic tools to efficiently differentiate between colonic carcinoma and colonic carcinoma associated with schistosomal infection among Egyptian patients. The parameters under investigation are interleukin 2 (IL-2), tumour necrosis factor alpha $(T N F-\alpha)$, carcinoembryonic antigen (CEA) levels, tissue telomerase, pyruvate kinase (PK), glucose-6-phosphate dehydrogenase (G-6-PD) and lactate dehydrogenase ( $L D H)$ enzyme activities. The results revealed a significant elevation in the level of the tumour markers IL-2,TNF- $\alpha$ and CEA as well as the activities of LDH, telomerase and G-6-PD among non-bilharzial and bilharzial colonic cancer groups, with a more potent effect in bilharzial infection-associated colonic cancer. A significant inhibition in PK activity was recorded in the same manner as compared to normal tissues. The efficacy of this biomarker was also evaluated through detecting sensitivity, specificity, negative and positive predictive values. In conclusion, schistosomal colonic carcinoma patients displayed more drastic changes in all parameters under investigation. The combination of the selected parameters succeeded in serving as biomarkers to differentiate between the two malignant types.

Key words: colon - cancer - intestinal Schistosoma - biomarkers - tumour marker

Colonic carcinoma is one of the most frequent malignancies in many tropical countries, where much evidence has suggested that schistosomiasis is implicated as an etiologic agent in colon cancer development ( $\mathrm{Li}$ et al. 2006, Cao et al. 2010).

Colonic schistosomiasis is a specific acute or chronic inflammatory reaction in response to Schistosoma ova that are deposited mainly in colorectal mucosa (Cao et al. 2010, Salim et al. 2010). Most of the published data refer to Schistosoma japonicum species in the induction of colonic cancer, but the evidence linking Schistosoma mansoni to colonic carcinoma occurrence is limited (Salim et al. 2010).

Among Egyptians, the incidence of colonic carcino$\mathrm{ma}$ is less than the incidence of bladder carcinoma. Colonic carcinoma occurs predominately in the Nile Delta region where the intermediate snail hosts of schistosomiasis are extremely abundant (Fedewa et al. 2009).

Tumour markers are substances, usually proteins, that are produced by the body in response to cancer growth or by the cancer tissue itself. These substances may be detected in blood, urine and tissue samples. Some tumour markers are specific for a particular type of cancer, while others are seen in several cancer types (Parekh et al. 2007).

+Corresponding author: manal_hamed@yahoo.com

Received 11 October 2010

Accepted 5 January 2011
Many investigators have focused their work on the enzymatic reactions in tumour cells and consider most of these enzymes to be tumour markers (Michael et al. 1980). Thangaraju et al. (2009) have reported that glycolytic enzymes are sharply intensified in colonic cancer, while key gluconeogenesis enzymes are sharply decreased. Some investigations have dealt with pyruvate kinase (PK) activity among different grades of malignancy in colorectal cancer (Shin et al. 2009). Glucose6-phosphate dehydrogenase (G-6-PD) has also been reported in a human adenocarcinoma cancer cell line (Vizán et al. 2009).

Telomerase is a ribonucleoprotein polymerase enzyme containing an integral RNA with a short template element that directs the de novo synthesis of telemetric repeats at the chromosomal ends. These repeats maintain the length of the telomeres and allow tumour cells to survive (Gonzalo et al. 2010). Therefore, telomeres are considered to be the clock that regulates how many times an individual cell can divide. Telomere sequences shorten each time the DNA replicates until they reach a critically short length, at which point the cell stops dividing and ages (Rampazzo et al. 2010). Under normal circumstances, telomerase is active in rapidly dividing embryonic cells and in stem cell populations, but not in terminally differentiated somatic cells. Much attention has recently focused on the hypothesis that the activity of this enzyme is necessary for cells to become immortal. This hypothesis predicts that telomerase activity should be detectable in malignant cells and tissues, but not in their normal counterparts, which slowly senesce and die (Yoshida et al. 1997). 
Carcinoembryonic antigen (CEA) is a glycoprotein involved in cell adhesion. CEA is normally produced during foetal development, but its production stops before birth. Therefore, CEA is not usually present in the blood of healthy adults. As a specialised glycoprotein, sialofucosylated glycoforms serve as functional colon carcinoma ligands (L-selectin and E-selectin); this function is critical to the metastatic dissemination of colon carcinoma cells (Thomas et al. 2008). Nielsen et al. (2011) determined that CEA is a valuable biomarker for the early detection of colorectal cancer.

Interleukin 2 (IL-2) is one of a group of related proteins made by leukocytes, such as $\mathrm{T}$ lymphocytes and other cells in the body. This protein increases the growth and activity of other $\mathrm{T}$ and $\mathrm{B}$ lymphocytes and affects the development of the immune system (Garcia-Tunon et al. 2004). The high expression of IL-2 and its receptors in tumour tissue is mediated by enhancing cell proliferation or inhibiting apoptosis, together with the enhancement of the anti-apoptotic factor gene (Bcl2-family gene) (Royuela et al. 2000). Several interleukins have been shown to induce the IL- 2 receptor (IL-2R) $\alpha$ in inflammatory processes and as this chine is necessary to form the high affinity of IL-2R, it enhances IL-2 signals (Garcia-Tunon et al. 2004).

Tumour necrosis factor alpha (TNF- $\alpha$ ), isolated 30 years ago, is a multifunctional cytokine that plays a key role in apoptosis and cell survival as well as in inflammation and immunity. Although named for its anti-tumour properties, TNF has been implicated in a wide spectrum of other diseases (van Horssen et al. 2006). In tumours, TNF- $\alpha$ may cause direct DNA damage, have anti-apoptotic or mitogenic activity, mediate tumour/stromal cell interactions and induce a range of cytokines and chemokines that promote tumour development. Moreover, TNF can synergise with growth factor such as transforming growth factor beta (Balkwill et al. 2006).

The aim of the present study was to identify biomarkers that could be helpful in the diagnosis and differentiation between colonic carcinoma and bilharzial-related colonic carcinoma among Egyptian patients. The effi- ciency of each biomarker was also evaluated. The work was extended to examine these biomarkers in S. manso$n i$-infected patients.

\section{PATIENTS, MATERIALS AND METHODS}

Clinical cases - All cases were of Egyptian colonic carcinoma and schistosomal infected patients attending in the Clinical and Medical Oncology Department, National Cancer Institute (NCI), Cairo University, Egypt.

Ethics - Surgical operations, biopsies and serum samples were subject to the ethical guidelines approved by the National Cancer Institute.

Pathological groups - Group 1: 30 colonic cancer patients with ages ranging from 31-66 years (18 males, ages 34-66 years, and 12 females, ages 31-58 years); group 2: 30 schistosomal colonic carcinoma patients with a median age of 35 years (18 females, ages 21-60 years, and 12 males, ages 30-67 years); group 3: 30 intestinal $S$. mansoni-infected patients. Their ages ranged from $42-$ 62 years (20 males, ages 42-60 years, and 10 females, ages 49-62 years); group 4: 30 individuals (26 males and 14 females with ages between 30-70 years) served as the control for all experimental groups. Unaffected colonic tissues (mucosa) were taken at the same time during the surgical operation on the patients.

Gross pathology - The surgical colonic carcinoma tissue and the biopsied intestinal schistosomiasis tissue were subjected to both pathological and histological examinations to determine the diagnosis and disease progress at the Clinical Pathology Department, NCI. The oriental cell microscopic slides were examined. The tumour grade and pathological differentiation are illustrated in Table I.

Preparation of tissue homogenate for PK, lactate dehydrogenase ( $L D H)$ and G-6-PD activities - Tissues were freed of necrotic debris and connective tissue and were immediately frozen at $-80^{\circ} \mathrm{C}$ until used. The specimens were homogenised in 4 vol of buffer containing $0.05 \mathrm{~mol} / \mathrm{L}$ tris hydrochloride, $0.10 \mathrm{~mol} / \mathrm{L} \mathrm{KCl}, 0.01$

TABLE I

Clinical data of different cases

\begin{tabular}{|c|c|c|c|c|c|c|c|}
\hline Clinical cases & \multicolumn{3}{|c|}{ Colonic carcinoma } & \multicolumn{2}{|c|}{ Bilharzial colonic carcinoma } & Intestinal schistosomiasis & Normal mucosa \\
\hline Cases (n) & \multicolumn{3}{|c|}{30} & \multicolumn{2}{|c|}{30} & 30 & 30 \\
\hline Age (years) & \multicolumn{3}{|c|}{$31-66$} & \multicolumn{2}{|c|}{$21-67$} & $40-62$ & $42-62$ \\
\hline \multicolumn{8}{|l|}{ Sex } \\
\hline Male & \multicolumn{3}{|c|}{18} & \multicolumn{2}{|c|}{18} & 20 & 26 \\
\hline Female & \multicolumn{3}{|c|}{12} & \multicolumn{2}{|c|}{12} & 10 & 14 \\
\hline Nods & $4(+v e)$ & & $26(-\mathrm{ve})$ & $14(+\mathrm{ve})$ & $16(-v e)$ & - & - \\
\hline Bilharziasis & \multicolumn{3}{|c|}{ Un-proven } & \multicolumn{2}{|c|}{ Proven } & Proven & Proven \\
\hline Grade & 24 & II & $\begin{array}{c}\text { III } \\
6\end{array}$ & I & $\begin{array}{c}\text { III } \\
8\end{array}$ & - & - \\
\hline \multirow[t]{2}{*}{ Pathology } & $\mathrm{Sq}$ & Tran & Adeno & $\mathrm{Sq}$ & Adeno & & \\
\hline & 14 & 10 & 6 & 10 & 8 & - & - \\
\hline
\end{tabular}

adeno: adenocarcinoma; sq: squamous cell carcinoma; tran: transition cell carcinoma; ve: absence; +ve: presence. 
$\mathrm{mol} / \mathrm{L} \mathrm{MgCl}_{2}, 0.1 \mathrm{~mol} / \mathrm{L}$ sucrose, $10 \mathrm{mmol} / \mathrm{L}$ glucose, $1 \mathrm{mmol} / \mathrm{L}$ EDTA and $2 \mathrm{mmol} / \mathrm{L}$ dithiothreitol. The homogenate was centrifuged for $5 \mathrm{~min}$ at $13,000 \mathrm{~g}$ and $4^{\circ} \mathrm{C}$ and the supernatant was used for enzyme assays.

Preparation of tissue homogenate for telomerase activity - Tissue samples were shock frozen in liquid nitrogen and stored at $-80^{\circ} \mathrm{C}$. Cryostat sections of $10-15 \mu \mathrm{m}$ thickness from frozen tissue samples were prepared. The sections were transferred into a sterile tube containing $200 \mu \mathrm{L}$ ice-cold lysate reagent, incubated on ice for $30 \mathrm{~min}$ and centrifuged at $16,000 \mathrm{~g}$ for $20 \mathrm{~min}$ at $4^{\circ} \mathrm{C}$.

Serum separation for tumour marker tests - A fasting venous blood sample $(5 \mathrm{~mL})$ was withdrawn and centrifuged. Sera were separated and stored at $-80^{\circ} \mathrm{C}$ until used.

Enzymatic assays - PK was assayed by the method of Imamura and Tanaka (1972), where the reaction velocity is determined in a LDH coupled assay system by measuring the decrease in absorbance at $340 \mathrm{~nm}$ caused by the oxidation of nicotinamide-adenine dinucleotide reduced form (NADH).

G-6-PD activity possesses dual coenzyme specificity, where the reaction velocity is determined by measuring the increase in absorbance at $340 \mathrm{~nm}$ caused by the reduction of NAD or nicotinamide-adenine dinucleotide phosphate (Haghighi \& Levy 1982).

LDH was assayed by the method of Babson and Babson (1973), where the reduction of NAD is coupled with the reduction of a tetrazolium salt [2-(p-iodophenyl)-3 -(p-nitrophenyl)-5-phenyl tetrazolium chloride] (INT). The resulting formazan of INT was measured colourimetrically at $503 \mathrm{~nm}$.

Telomerase activity was measured by a polymerase chain reaction (PCR)-enzyme-linked immunosorbent assay (ELISA) technique using the telomerase repeat amplification protocol according to Gelmini et al. (1998). This method is based on the use of a sensitive fluorochrome that selectively binds double-stranded DNA. The measurement of DNA concentration in postPCR samples can be considered quantitatively related to telomerase activity.

Protein concentration was determined colourimetrically by the method of Bradford (1976), where bovine serum albumin was used as a standard protein and the developed colour was read colourimetrically at $595 \mathrm{~nm}$.

Tumour markers assays - The measurement of serum IL-2 employed the quantitative sandwich enzyme immunoassay technique. A monoclonal antibody specific for IL-2 was used. Standards and samples were pipetted into the wells and any IL-2 present was bound by the immobilised antibody. An enzyme-linked polyclonal antibody specific for IL-2 and tetramethylbenzidine as a substrate were added. The developed colour was measured at 450 $\mathrm{nm}$ using a microtiter plate reader (Yang et al. 1991).

The measurement of serum TNF- $\alpha$ employed the quantitative enzyme-linked immunosorbent technique. A monoclonal antibody specific for human TNF- $\alpha$ was pre-coated onto a microplate. Standards and samples were pipetted into the wells and TNF- $\alpha$ present in a sample bound to the wells through the immobilised antibody. Anti-human TNF- $\alpha$ antibody and the tetrameth- ylbenzidine substrate were added. The developed colour was measured at $450 \mathrm{~nm}$ using a microtiter plate reader (Bonavida 1991).

The measurement of serum CEA was based on the principle of a solid phase ELISA. The assay system utilises a monoclonal antibody directed against a distinct antigenic determinant on the intact CEA molecule. The test sample is allowed to react simultaneously with two antibodies, resulting in the CEA molecules being sandwiched between the solid phase and enzyme-linked antibodies. Tetramethylbenzidine was added as a substrate and the developed colour was measured at $450 \mathrm{~nm}$ (Zamcheck \& Martin 1981).

Statistical analysis - Data from 30 patients in each group were expressed as the mean \pm standard deviation. The statistical analysis was performed using one way analysis of variance accompanied by a post-hoc test in the SPSS Computer Program. The least significance value between groups was at $\mathrm{p} \leq 0.05$.

\section{RESULTS AND DISCUSSION}

The incidence of colon cancer among Egyptians is less than the reported incidence of bladder cancer (Fedewa et al. 2009). Colonic carcinoma associated with bilharzial lesions was $19 \%$ of all colonic cancer (EL-Bolkainy et al. 1982). Intestinal schistosomiasis occurs as a result of the deposition of Schistosoma ova in submucosa producing a granulomatous reaction, mucosal edema, haemorrhage and ulceration in the bowel wall. In the advanced stage, a thickened bowel wall, polyps or enteric cavity stricture can be detected (Yosry 2006). In our study and according to the pathological data received from Clinical and Medical Oncology Department, Schistosoma ova were deposited with infiltration of lymphocytes and plasma cells in the submucosa and lamina propria. In addition, atrophy of the intestinal mucosa epithelium, reduction of intestinal glands and different degrees of fibrosis were also observed in the intestinal schistosomiasis group. In colonic schistosomiasis patients, massive egg deposition, an intensive degree of fibrosis, hyperplasic polyps, canalicular and tubulovillous adenoma with intraepithelial neoplastic change were detected. In contrast, different types of papillary, mucinous and tubular adenocarcinoma were observed in colonic carcinoma patients.

Cheever and Andrade (1967) and Chassot et al. (1998) showed that schistosomiasis-related intestinal polyps are frequently seen in Egyptian cases of intestinal schistosomiasis, which is different compared to most other endemic areas. Colonic involvement has been demonstrated to be meagre in Brazilian cases, rarely exhibiting polyps, and with no signs of a particular relationship with colonic cancer. In other African countries, where $S$. haematobium are endemic, severe intestinal involvement is not frequent. In China, a high incidence of colorectal cancer in regions with endemic S. japonicum was recorded, where patients with chronic Schistosomiasis japonica have a more than three times greater risk of developing colon cancer than those with no previous exposure to schistosomal infection (Salim et al. 2010). Therefore, the difference in parasite strains, intensity of 
infection, concomitant infections (including S. haematobium) and environmental conditions may be important in determining the varying patterns of the disease (Cheever \& Andrade 1967).

From another point of view, the problem of bilharziasis and its various aspects needs careful clinical studies to clarify its effect on the biochemical features of tumour development (Salim et al. 2010). In the present study, LDH showed a significant elevation by $93.90 \%, 169.29 \%$ and $36.95 \%$ in colon cancer, bilharzial-related colon cancer and intestinal schistosomiasis colon tissue, respectively. In contrast, PK showed a significant reduction by $24.57 \%, 42.85 \%$ and $18.85 \%$ in colon cancer, bilharzialrelated colon cancer and intestinal schistosomiasis colon tissue, respectively (Fig. 1, Table II). These findings were in accordance with Thangaraju et al. (2009), who recorded that the intracellular levels of pyruvate in colon cancer cells are much lower than those in non-malignant cells. They attributed the decrease in pyruvate level to the expression of the LDH enzyme involved in the generation and metabolism of pyruvate. They added that cancer cells generate lactate purposely to reduce the intracellular levels of pyruvate. The conversion of pyruvate into lactate is not the only mechanism by which cancer cells manage to keep the pyruvate levels low. These cells also differentially express PK splice variants, PKM1 and PKM2, such that the activity of PK, which converts phosphoenolpyruvate into pyruvate, is low. Elevation of LDH activity in malignant and bilharzial colonic carcinoma can be used as an indicator for the stimulation of anaerobic pathways in cases of abnormal growth of human cancer cells (Thangaraju et al. 2009). Aly et al. (2004) found the same pattern of LDH promotion in bladder carcinoma and $S$. haematobium-associated bladder cancer. The increase in LDH activity in bilharziasis can be related to the fact that the Schistosoma parasite is a homolactate form enter, producing lactate as a sole metabolic end that can in turn increase the rate of the enzymatic activity (Nabih \& el-Ansary 1992). The recorded LDH increased more significantly in cancerous tissue associated with bilharzial infection than in malignant tissue. This increase in LDH was attributed to the enhancement of anaerobic glycolysis by Schistosoma toxins, suppression of pyruvate oxi- dative metabolism in mitochondria (where the mitochondrial enzymes were also affected) (Hamed et al. 2010), marked disturbance in glycolytic pathways due to cancer complications and the overproduction and proliferation of cancer cells (Aly et al. 2004).

Regarding G-6-PD, the present results recorded a significant increase by $38.35 \%, 58.63 \%$ and $19.47 \%$ in colonic carcinoma tissue, bilharzial-related colonic carcinoma and intestinal schistosomiasis, respectively (Fig. 1, Table II). In agreement with the present study, Frederiks et al. (2007) reported a massive ultrastructural localization of G-6-PD in the cytoplasm of colon carcinoma cells, whereas human colon cancer cells contained five times higher G-6-PD activity than hepatoma cells. Vizán et al. (2009) found that G-6-PD, the key enzyme of the oxidative branch of the pentose phosphate pathway (which is necessary for nucleotide synthesis), is enhanced during cell cycle progression of the human colon cancer cell line. This enhanced enzyme activity coincides with an increased ratio of the pentose monophosphate to the hexose monophosphate pool during late G1 and S phases of cell cycle, suggesting a potential role for pentose phosphates in proliferation signalling. Geraci et al. (2010) detected genetic heterogeneity among G-6-PD transcripts in colon and colorectal tumours. In case of S. mansoni infection, G-6-PD was significantly increased (Shaheen et

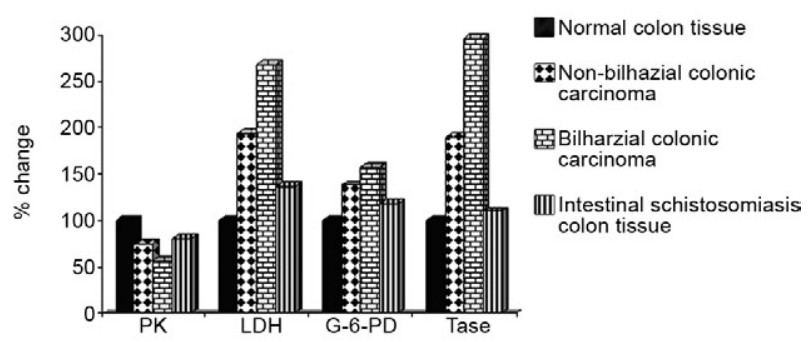

Fig. 1: percentage changes of enzymatic biomarkers in different clinical cases as compared to normal group. G-6-PD: glucose-6phosphate dehydrogenase; LDH: lactate dehydrogenase; PK: pyruvate kinase; Tase: telomerase.

TABLE II

Enzymatic biomarkers in bilharzial and non-bilhazial colonic carcinoma Egyptian patients

\begin{tabular}{lcccccc}
\hline Parameters & $\begin{array}{c}\text { Normal } \\
\text { tissue }^{a}\end{array}$ & $\begin{array}{c}\text { Non-bilharzial } \\
\text { colon cancer }^{b}\end{array}$ & $\begin{array}{c}\text { Bilharzial } \\
\text { colon cancer }^{c}\end{array}$ & $\begin{array}{c}\text { Intestinal } \\
\text { schistosomiasis }^{d}\end{array}$ & $\begin{array}{c}\text { ANOVA } \\
\text { F-ratio }^{2}\end{array}$ & $p^{p}$ \\
\hline Pyruvate kinase & $17.50 \pm 2.31^{b, c, d}$ & $13.20 \pm 2.51^{a, c, d}$ & $10.00 \pm 2.78^{a, b, d}$ & $14.20 \pm 2.41^{a, b, c}$ & 43.72 & $<0.0001$ \\
Lactate dehydrogenase & $8.20 \pm 0.95^{b, c, d}$ & $15.90 \pm 0.94^{a, c, d}$ & $22.00 \pm 1.15^{a, b, d}$ & $11.23 \pm 1.12^{a, b, c}$ & 1242.80 & $<0.0001$ \\
Glucose-6- phosphate dehydrogenase & $4.98 \pm 1.21^{b, c, d}$ & $6.89 \pm 0.60^{a, c, d}$ & $7.90 \pm 0.30^{a, b, d}$ & $5.95 \pm 1.21^{a, b, c}$ & 120.98 & $<0.0001$ \\
Telomerase & $0.29 \pm 0.01^{b, c}$ & $0.55 \pm 0.06^{a, c, d}$ & $0.86 \pm 0.60^{a, b, d}$ & $0.32 \pm 0.05^{b, c}$ & 190.09 & $<0.0001$ \\
\hline
\end{tabular}

$a$ - $d$ : significant difference between groups at $\mathrm{p} \leq 0.05$. Data are mean \pm standard deviation of 30 patients in each group. Values are expressed as $\mu \mathrm{mol} / \mathrm{mg}$ protein. Statistical analysis is carried out using one way analysis of variance (ANOVA) with post-hoc test, SPSS Computer Program. 
al. 1989) due to an elevation in glycogen synthesis, which enhanced enzyme activity. In patients with bilharzial colon carcinoma, G-6-PD was markedly elevated. This elevation was attributed to the synchronised effect of both diseases, accumulation of hepatic glycogen and enhancement of cell proliferation. Schistosoma toxins and ova deposition may also act as a signal on gene expression, leading to activation of transcription of a specific DNA sequence into mRNA. Gene activation is an effective way to enhance enzyme activity (Hoek et al. 1997).

Telomerase is a ribonucleoprotein that synthesises TTAGGG tandem repeats at each telomeric region to reextend the telomere to its original length. The enzyme is active in embryonic cells and in stem cells, but its activity is undetectable in normal, terminally differentiated somatic cells (Kim et al. 1994). Cells that can overcome this limitation have the potential for prolonged survival, indefinite proliferation and tumour development. Hence, if the "telomere hypothesis" applies to human malignancy, one might predict that telomerase activity would be detectable in the initial stages of neoplasia and could therefore be a particularly useful marker for early diagnosis (Yoshida et al. 1997).

The telomerase activity, in the present study, was enhanced by $89.65 \%, 196.55 \%$ and $10.34 \%$ for the cases of colonic cancer, bilharzial colonic cancer and in bilharzial colon tissues, respectively (Fig. 1, Table II). In agreement with our results, Yoshida et al. (1997) have detected telomerase in a wide range of malignancies, including those of the gastrointestinal tract, breast and lung. Rampazzo et al. (2010) have suggested that telomere shortening is a key initial event in colorectal carcinogenesis, where the extent of telomere erosion is related to the tumour origin site and may be influenced by the mismatch repair pathway. Gonzalo et al. (2010) have found that long-standing inflammatory bowel disease in patients with high risk for colorectal cancer leads to an overexpression of human telomerase reverse transcriptase in non-affected colorectal mucosa, suggesting its potential usefulness as a biomarker for the risk of malignant transformation. In contrast to the results of Gonzalo et al. (2010), Yoshida et al. (1997) have detected strong enzyme activity representing $92 \%$ of co- lonic carcinoma patients with no sign of activity in cases of inflammatory bowel disease, suggesting its potency as a good marker for the detection of colon carcinoma regardless of the tumour stage or the histological type of tumour. In parallel with the present finding, Shaker et al. (2009) have recorded an increase in telomerase activity in schistosomal-associated bladder cancer in comparison to non schistosomal-associated bladder cancer. The higher incidence of telomerase in bilharzial colonic cancer patients than in colonic carcinoma patients may be due to the effect of Schistosoma toxins, which act as a stimulus for activating the human telomerase reverse transcriptase protein that provokes enzyme activity in addition to the role of enzyme initiation in cancer cells.

In the case of tumour markers, IL-2 displayed a significant elevation by $92.14 \%, 111.29 \%$ and $15.40 \%$ in non-bilharzial colon cancer, bilharzial colon cancer and intestinal schistosomiasis, respectively (Fig. 2, Table III). These data are in accordance with Berghella et al. (1994), who have stated that IL-2 levels are significantly correlated with the stage of colon cancer disease, showing an increase from stage I to stage IV. Reichert et al. (1998) have determined that carcinoma cells synchronised in the $\mathrm{G}_{2} / \mathrm{M}$-phase of the cell cycle express significantly more intracytoplasmic IL-2. Moreover, Johnson et al. (2009) have mentioned that treatment of mice bearing colon adenocarcinoma with a tumour-specific monoclonal antibody fused to IL-2 causes greater suppression

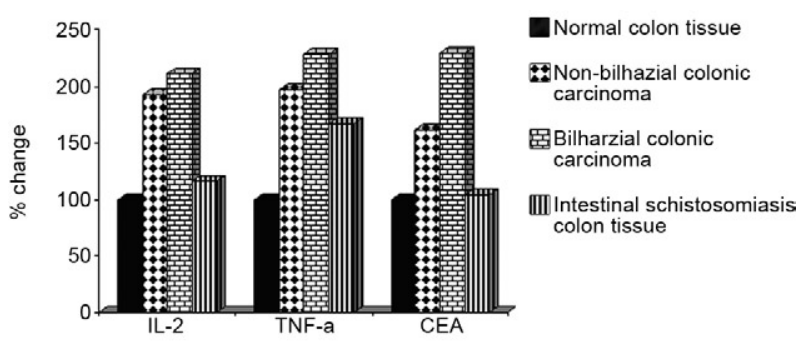

Fig. 2: percentage changes of tumour biomarkers in different clinical cases as compared to normal group. CEA: carcinoembryonic antigen; IL-2: interleukin 2; TNF- $\alpha$ : tumour necrosis factor alpha.

TABLE III

Tumor biomarkers in bilharzial and non-bilhazial colonic carcinoma Egyptian patients

\begin{tabular}{lcccccc}
\hline Parameters & $\begin{array}{c}\text { Normal } \\
\text { tissue }^{a}\end{array}$ & $\begin{array}{c}\text { Non-bilharzial } \\
\text { colon cancer }^{b}\end{array}$ & $\begin{array}{c}\text { Bilharzial } \\
\text { colon cancer }^{c}\end{array}$ & $\begin{array}{c}\text { Intestinal } \\
\text { schistosomiasis }^{d}\end{array}$ & $\begin{array}{c}\text { ANOVA } \\
\text { F-ratio }^{2}\end{array}$ & $\begin{array}{c}\text { p } \\
\text { IL-2 }\end{array}$ \\
TNF- $\alpha$ & $38.70 \pm 3.11^{b, c, d}$ & $92.60 \pm 1.66^{a, c, d}$ & $102.90 \pm 1.94^{a, b, d}$ & $56.20 \pm 2.80^{a, b, c}$ & 4856.10 & $<0.0001$ \\
CEA & $3.20 \pm 0.77^{b, c, d}$ & $6.30 \pm 0.81^{a, c, d}$ & $7.30 \pm 1.22^{a, b, d}$ & $5.35 \pm 0.30^{a, b, c}$ & 216.22 & $<0.0001$ \\
\hline
\end{tabular}

$a$ - $d$ : significant difference between groups at $\mathrm{p} \leq 0.05$. Data are mean \pm standard deviation of 30 patients in each group. Values of interleukin 2 (IL-2) and tumour necrosis factor alpha (TNF- $\alpha$ ) are expressed as pg/mL. Carcinoembryonic antigen (CEA) is expressed as $\mathrm{ng} / \mathrm{mL}$. Statistical analysis is carried out using one way analysis of variance (ANOVA) with post-hoc test, SPSS Computer Program. 
of tumour growth and enhances survival rate. SilveiraLemos et al. (2008) and Allam (2009) have observed significant elevations of IL-2 after $S$. mansoni infection in human and mice. In addition, Elshazley et al. (2006) have recorded a significant increase in IL-2 among different stages of schistosomiasis; in chronic schistosomiasis with hepatitis B or hepatitis C, a higher level of significance ( $\mathrm{p}$ $<0.001)$ was observed. Stavitsky and Harold (1988) explain this phenomenon according to distinct signals from granulomatous inflammation that enhances proliferation of $\mathrm{T}$ lymphocytes and lymphokine gene expression. These enhancements promote IL-2 production, as there is a complex interplay between IL-2 and inflammatory signals during infection (Pipkin et al. 2010). These data are in line with our data through the elevation of IL-2 in schistosomal infection and the higher significance value in schistosomal colonic carcinoma patients.

Almost two decades ago, TNF was identified as a protein produced by the immune system that plays a major role in the suppression of tumour cell proliferation. Extensive research since then has revealed that TNF is a major mediator of inflammation, viral replication, tumour metastasis, transplant rejection, rheumatoid arthritis and septic shock (Aggarwal et al. 2002). In our study, TNF- $\alpha$ was significantly increased by $96.87 \%, 128.12 \%$ and $67.18 \%$ in non-schistosomal colon cancer, schistosomal colon cancer and intestinal bilharziasis colon tissue, respectively (Fig. 2, Table III). These data are in accordance with Talero et al. (2011), who have recorded the highest production of TNF- $\alpha$ in mice experimentally induced with colorectal carcinoma. In addition, Kemik et al. (2010) have stated that TNF-alpha was significantly increased in the serum of cachectic patients with colon cancer. The recorded high level of TNF- $\alpha$ in schistosomal colon cancer patients was in agreement with Torben and Hailu (2007). They attributed the increased level of this inflammatory cytokine to toxins elevated by egg deposition and granulomatous reaction, which enhanced the induction of tissue fibrosis through propelling the hepatic satellite cells. This process also indirectly induces the production of other fibrogenic factors, such IL-1 and IL- 6 (Kimura et al. 2003). Moreover, Davies et al. (2004) have reported that TNF- $\alpha$ essentially functions as a trophic factor for maintaining the viability of adult Schistosoma worms, in addition to its role as a mitogen and promoter of tumour development in schistosomiasis-associated carcinoma (Balkwill et al. 2006).

CEA, a tumour-associated antigen, is a widely used serum biomarker for colorectal cancer. Interestingly, CEA has also been shown to correlate with the differentiation state of normal colon and in colon cancer cell lines. In the normal colonic mucosa, CEA expression showed a crypt-surface distribution. CEA expression was strong in surface epithelial cells and goblet cells of the upper crypts, while very weak in the mid crypt and at the base. Cell lines with high expression of CEA showed shuttle-shape morphologic changes with long or dendritic-like cytoplasmic processes (Ruan et al. 2010). CEA, in the present study, displayed an enhancement of $61.64 \%, 130.13 \%$ and $4.11 \%$ in colon cancer not associated with bilharzia, bilharzial-associated colon cancer and intestinal schistosomiasis colon tissue, respectively. Thirunavukarasu et al. (2010) have recorded a significant increase of CEA in medullary carcinoma of the colorectum, which is a new histological type of adenocarcinoma characterised by poor glandular differentiation and intraepithelial lymphocytic infiltrate. Nielsen et al. (2010) have recommended the use of a combination of plasma tissue inhibitor of metalloproteinases-1 and CEA for the detection of colorectal cancer and especially in colon cancer. Chen et al. (2010) have added that the membrane protein profile of colorectal carcinoma and neighbouring normal mucosa from colorectal cancer patients is easily differentiated by the over-expression of CEAs. Sarkar et al. (2010) have mentioned that vaccination with neem leaf glycoprotein matured CEA pulsed dendritic cells enhances antigen-specific humoral and cellular immunity against CEA and restricts the growth of CEA $(+)$ murine tumours. Over-expression of CEA in colonic carcinoma associated with schistosomiasis may be due

TABLE IV

Evaluation of enzymatic and tumor markers as diagnostic tools among different groups

\begin{tabular}{lccccc}
\hline Parameters & $\begin{array}{c}\text { Sensitivity } \\
(\%)\end{array}$ & $\begin{array}{c}\text { Specificity }^{b} \\
(\%)\end{array}$ & $\begin{array}{c}\text { Negative predictive value }^{c} \\
(\%)\end{array}$ & $\begin{array}{c}\text { Positive predictive value }^{d} \\
(\%)\end{array}$ & Cut-off value $^{e}$ \\
\hline PK & 24 & 64 & 41.11 & 46.34 & $8.23 \mu \mathrm{mol} / \mathrm{mg} \mathrm{protein}$ \\
LDH & 20 & 61 & 43.24 & 49.25 & $4.32 \mu \mathrm{mol} / \mathrm{mg} \mathrm{protein}$ \\
G-6-PD & 22 & 60.14 & 44.15 & 46.28 & $1.60 \mu \mathrm{mol} / \mathrm{mg} \mathrm{protein}$ \\
Telomerase & 72 & 83 & 83.20 & 88.12 & $0.11 \mu \mathrm{mol} / \mathrm{mg} \mathrm{protein}$ \\
IL-2 & 71 & 80.30 & 78.40 & 85.50 & $7.9 \mathrm{pg} / \mathrm{mL}$ \\
TNF- $\alpha$ & 73 & 79 & 60.70 & 78.20 & $2.9 \mathrm{pg} / \mathrm{mL}$ \\
CEA & 74 & 81.70 & 64.50 & 73.20 & $2.4 \mathrm{ng} / \mathrm{mL}$
\end{tabular}

$a$ : true positives/true positives + false negatives; $b$ : true negatives/true negatives + false positives; $c$ : true negatives/true negatives + false negatives; $d$ : true positives/true positives + false positives; $e$ : is the minimal value of each parameter; CEA: carcinoembryonic antigen; G-6-PD: glucose-6-phosphate dehydrogenase; IL-2: interleukin-2; LDH: lactate dehydrogenase; PK: pyruvate kinase; TNF- $\alpha$ : tumour necrosis factor alpha. 
to the advanced stage of tumour progression related to schistosomiasis. Metastasis or the development of other carcinomas due to schistosomiasis complications may also be taken into consideration.

The evaluation of enzymatic and tumour markers as diagnostic tools among different groups is clearly illustrated in Table IV. Telomerase, IL-2, TNF- $\alpha$ and CEA displayed potent values in the diagnosis of bilharzial and non-bilharzial colon cancer, while PK, G-6-PD and LDH to some extent succeeded in differential diagnosis.

In conclusion, the selected enzymatic biomarkers along with the commonly known tumour markers play a potential role in differentiating between bilharzial and non-bilharzial colonic carcinomas. Schistosomiasisassociated colon cancer displayed drastic changes in all biomarkers compared with colon carcinoma. Detailed studies must be done among colon cancer associated with schistosomiasis infection, especially in developing countries where $S$. mansoni is endemic, to establish new biomarkers for early diagnosis of the disease.

\section{REFERENCES}

Aggarwal BB, Shishodia S, Ashikawa K, Bharti AC 2002. The role of $\mathrm{TNF}$ and its family members in inflammation and cancer: lessons from gene deletion. Curr Drug Targets Inflamm Allergy 1: 327-341.

Allam G 2009. Immunomodulatory effects of curcumin treatment on murine schistosomiasis mansoni. Immunobiology 214: 712-727.

Aly HF, Hamed MA, Ahmed SA, Khaled HM 2004. Selected some biochemical parameters used as new markers for diagnosis of bladder cancer. Egypt J Schistosomiasis Infect Endem Dis 26: 41-63.

Babson AL, Babson SR 1973. Kinetic colorimetric measurement of serum lactate dehydrogenase activity. Clin Chem 19: 766-769.

Balkwill F 2006. TNF- $\alpha$ in promotion and progression of cancer. Cancer Metastasis Rev 25: 409-416.

Berghella AM, Pellegrini P, Piancatelli D, Maccarone D, Del Beato T, Giubilei D, Pomidori A, Adorno D, Casciani CU 1994. Progression mechanisms in colon cancer: soluble interleukin-2 (IL-2) receptor, IL-2 plus anti-CD3 proliferative response and tumor stage correlations. Cancer Immunol Immunother 38: 160-166.

Bonavida B 1991. Immunomodulatory effect of tumor necrosis factor. Biotherapy 3: 127-133.

Bradford MM 1976. A rapid and sensitive method for the quantitation of microgram quantities of protein utilizing the principle of protein-dye binding. Anal Biochem 72: 248-254.

Cao J, Liu WJ, Xu XY, Zou XP 2010. Endoscopic findings and clinicopathologic characteristics of colonic schistosomiasis: a report of 46 cases. World J Gastroenterol 16: 723-727.

Chassot CA, Christiano CG, Barros MS, Rodrigues CJ, Corbett CEP 1998. Colon polyps in Schistosoma haematobium schistosomiasis. Mem Inst Oswaldo Cruz 93 (Suppl. I): 289-291.

Cheever AW, Andrade ZA 1967. Pathological lesions associated with Schistosoma mansoni infection in man. Trans Roy Soc Trop Med Hyg 61: 629-639.

Chen JS, Chen KT, Fan CW, Han CL, Chen YJ, Yu JS, Chang YS, Chien CW, Wu CP, Hung RP, Chan EC 2010. Comparison of membrane fraction proteomic profiles of normal and cancerous human colorectal tissues with gel-assisted digestion and iTRAQ labeling mass spectrometry. FEBS J 277: 3028-3038.
Davies SJ, Lim KC, Blank RB, Kim JH, Lucas KD, Hernandez DC, Sedgwick JD, McKerrow JH 2004. Envolvement of TNF in limiting liver pathology and promoting parasite survival during schistosome infection. Int J Parasitol 34: 27-36.

El-Bolkainy MN, Chu EW, Ghoneim MA, Ibrahim AS 1982. Cytologic detection of bladder cancer in a rural Egyptian population infected with schistosomiasis. Acta Cytol 26: 303-310.

Fedewa SA, Soliman AS, Ismail K, Hablas A, Seifeldin IA, Ramadan M, Omar HG, Nriagu J, Wilson ML 2009. Incidence analyses of bladder cancer in the Nile delta region of Egypt. Cancer Epidemiol 33: 176-181.

Frederiks WM, Vreeling-Sindelárová H, Van Noorden CJ 2007. Loss of peroxisomes causes oxygen insensitivity of the histochemical assay of glucose-6-phosphate dehydrogenase activity to detect cancer cells. J Histochem Cytochem 55: 175-181.

Garcia-Tunon I, Ricote M, Ruiz A, Fraile B, Paniagua R, Royuela M 2004. Interleukin-2 and its receptor complex ( $\alpha, \beta$ and $\gamma$ chains) in in situ and infiltrative human breast cancer: an immunohistochemical comparative study. Breast Cancer Res 6: R1-R7.

Gelmini S, Caldini A, Becherini L, Capaccioli S, Pazzagli M, Orlando C 1998. Rapid quantitative nonisotopic assay for telomerase activity in human tumors. Clin Chem 44: 2133-2138.

Geraci G, D’Elia I, del Gaudio R, Di Giaimo R 2010. Evidence of genetic instability in tumors and normal nearby tissues. PLos One 5: e9343.

Gonzalo V, Petit A, Castellví-Bel S, Pellisé M, Muñoz J, Piñol C, Rodríguez-Moranta F, Clofent J, Balaguer F, Giráldez MD, Ocaña T, Serradesanferm A, Grau J, Reñé JM, Panés J, A 2010. Telomerase mRNA expression and immunohistochemical detection as a biomarker of malignant transformation in patients with inflammatory bowel disease. Gastroenterol Hepatol 33: 288-296.

Haghighi B, Levy HR 1982. Glucose 6-phosphate dehydrogenase from Leuconostoc mesenteroides. Kinetics of reassociation and reactivation from inactive subunits. Biochemistry 21: 6429-6434.

Hamed MA, Ali HF, Ali SA, El-Rigal N, Rizk MZ 2010. Biomphalaria alexandrina snails as immunogens against Schistosoma mansoni infection in mice. Mem Inst Oswaldo Cruz 105: 879-888.

Hoek RM, van Kesteren RE, Smit AB, de Jong-Brink M, Geraerts WPM 1997. Altered gene expression in the host brain caused by a trematode parasite: neuropeptide genes are preferentially affected during parasitosis. Proc Natl Acad Sci 94: 14072-14076.

Imamura K, Tanaka T 1972. Multimollecular form of pyruvate kinase from rat and other mammalian tissues. J Biocheim 71: 1043-1051.

Johnson EE, Yamane BH, Buhtoiarov IN, Lum HD, Rakhmilevich AL, Mahvi DM. Gillies SD, Paul M Sondel PM 2009. Radiofrequency ablation combined with KS-IL2 immunocytokine (EMD 273066) results in an enhanced antitumor effect against murine colon adenocarcinoma. Clin Cancer Res 15: 4875-4884.

Kemik O, Sumer A, Kemik AS, Hasirci I, Purisa S, Dulger AC, Demiriz B, Tuzun S 2010. The relationship among acute-phase response proteins, cytokines and hormones in cachectic patients with colon cancer. World J Surg Oncol 8: 85.

Kim NW, Piatyszek MA, Prowse KR, Harley CB, West MD, HO PLC, Coviello GM, Wright WE, Weinrich SL, Shay JW 1994. Specific association of human telomerase activity with immortal cells and cancer. Science 266: 2011-2015.

Kimura M, Haisa M, Uetsuka H, Takaoka M, Ohkawa T, Kawashima R, Yamatsuji T, Gunduz M, Kaneda Y, Tanaka N, Naomoto Y 2003. TNF combined with IFN-alpha accelerates NF-kappaBmediated apoptosis through enhancement of Fas expression in colon cancer cells. Cell Death Differ 10: 718-728. 
Li WC, Pan ZG, Sun YH 2006. Sigmoid colonic carcinoma associated with deposited ova of Schistosoma japonicum: a case report. World J Gastroenterol 12: 6077-6079.

Michael A, Gerber MD, Swan N, Thung MD 1980. Enzyme patterns in human hepatocellular carcinoma. Am J Pathol 98: 395-400.

Nabih I, el-Ansary A 1992. Metabolic end-products in parasitic helminths and their intermediate hosts. Comp Biochem Physiol B 101: 499-508.

Nielsen HJ, Brünner N, Jorgensen LN, Olsen J, Rahr HB, Thygesen K, Hoyer U, Laurberg S, Stieber P, Blankenstein MA, Davis G, Dowell BL, Christensen IJ 2011. Plasma TIMP-1 and CEA in detection of primary colorectal cancer: a prospective, population based study of 4509 high-risk individuals. Scand J Gastroenterol 46: 60-69.

Parekh DJ, Ankerst DP, Troyer D 2007. Biomarkers for prostate cancer detection. J Urol 178: 2252-2259.

Pipkin ME, Sacks JA, Cruz-Guilloty F, Lichtenheld MG, Bevan MJ, Rao Ae 2010. Interleukin-2 and inflammation induce distinct transcriptional programs that promot the differentiation of effector cytolytic T cells. Immunity 29: 79-90.

Rampazzo E, Bertorelle R, Serra L, Terrin L, Candiotto C, Pucciarelli S, Del Bianco P, Nitti D, De Rossi A 2010. Relationship between telomere shortening, genetic instability and site of tumour origin in colorectal cancers. Br J Cancer 102: 1300-1305.

Reichert TE, Watkins S, Stanson J, Johnson JT, Whiteside TL 1998. Endogenous IL-2 in cancer cells: a marker of cellular proliferation. J Histochem Cytochem 46: 603-611.

Royuela M, De Miguel MP, Bethencourt FR, Fraile B, Arenas MI, Paniagua R 2000. IL-2, its receptors and bcl-2 and bax genes in normal, hyperplastic and carcinomatous human prostates: immunohistochemical comparative analysis. Growth Factors 18: 135-146.

Ruan W, Zhu S, Wang H, Xu F, Deng H, Ma Y, Lai M 2010. IGFBP$\mathrm{rP1}$, a potential molecule associated with colon cancer differentiation. Mol Cancer 9: e281.

Salim HO, Hamid HK, Mekki SO, Suleiman SH, Ibrahim SZ 2010. Colorectal carcinoma associated with schistosomiasis: a possible causal relationship. World J Surg Oncol 13: 68.

Sarkar K, Goswami S, Roy S, Mallick A, Chakraborty K, Bose A, Baral R 2010. Neem leaf glycoprotein enhances carcinoembryonic antigen presentation of dendritic cells to $\mathrm{T}$ and $\mathrm{B}$ cells for induction of anti-tumor immunity by allowing generation of immune effector/memory response. Int Immunopharmacol 10: 865-874.

Shaheen AA, Ebeid FA, Fahim AT 1989. Effect of praziquantel on some aspects of carbohydrate metabolism in mice infected with Schistosoma mansoni. Pharmacol Res 21: 263-270.

Shaker OG, Hammam O, Salehd A, el-Leithy T, Wishahi M 2009. Possible role of telomerase and sFas in pathogenesis of various bladder lesions associated with schistosomiasis. Clin Biochem 42: 864-872.

Shin YK, Yoo BC, Hong YS, Chang HJ, Jung KH, Jeong SY, Park JG 2009. Upregulation of glycolytic enzymes in proteins secreted from human colon cancer cells with 5-fluorouracil resistance. Electrophoresis 30: 2182-2192.
Silveira-Lemos D, Teixeira-Carvalho A, Martins-Filho OA, Alves Oliveira LF, Costa-Silva MF, Matoso LF, de Souza LJ, Gazzinelli A, Correa-Oliveira R 2008. Eosinophil activation status, cytokines and liver fibrosis in Schistosoma mansoni infected patients. Acta Trop 108: 150-159.

Stavitsky A, Harold WW 1988. Deficiency of interleukin-2 activity upon addition of soluble egg antigen to cultures of spleen cells from mice infected with Schistosoma japonicum. Infect Immun 56: 1778-1784.

Talero E, Sanchez-Fidalgo S, Villegas I, de la Lastra CA, Illanes M, Motilva V 2011. Role of different inflammatory and tumor biomarkers in the development of ulcerative colitis-associated carcinogenesis. Inflamm Bowel Dis 17: 696-710.

Thangaraju M, Carswell KN, Prasad PD, Ganapathy V 2009. Colon cancer cells maintain low levels of pyruvate to avoid cell death caused by inhibition of HDAC1/HDAC3. J Biochem 417: 379-389.

Thirunavukarasu P, Sathaiah M, Singla S, Sukumar S, Karunamurthy A, Pragatheeshwar KD, Lee KK, Zeh H, Kane KM, Bartlett DL 2010. Medullary carcinoma of the large intestine: a population based analysis. Int $J$ Oncol 37: 901-907.

Thomas SN, Zhu F, Schnaar RL, Alves CS, Konstantopoulos K 2008. Carcinoembryonic antigen and $\mathrm{CD} 44$ variant isoforms cooperate to mediate colon carcinoma cell adhesion to E- and L-selectin in shear flow. J Biol Chem 283: 15647-15655.

Torben W, Hailu A 2007. The development of hepatic granulomas in $20 \mathrm{Krad}$ irradiated Schistosoma mansoni cercaria vaccinated grivet monkeys (Cercopithecus aethiops aethiops). Exp Parasitol 117: 376-381.

van Horssen R, ten Hagen TLM, Eggermont AMM 2006. TNF- $\alpha$ in cancer treatment: molecular insights, antitumor effects and clinical utility. The Oncologist 11: 397-408.

Vizán P, Sánchez-Tena S, Alcarraz-Vizán G, Soler M, Messeguer R, Pujol MD, Lee WN, Cascante M 2009. Modulation of pentose phosphate pathway during cell cycle progression in human colon adenocarcinoma cell line HT29. Int J Cancer 124: 2789-2796.

Yang SC, Grimm EA, Parkinson DR, Carinhas J, Fry KD, Mendiguren-Rodriguez A, Licciardello J, Owen-Schaub LB, Hong WK, Roth JA 1991. Clinical and immunomodulatory effects of combination immunotherapy with low-dose interleukin 2 and tumor necrosis factor alpha in patients with advanced non-small cell lung cancer: a phase I trial. Cancer Res 51: 3669-3676.

Yoshida K, Sugino T, Goodison S, Warren BF, Nolan D, Wadsworth S, Mortensen NJ, Toge T, Tahara E, Tarin D 1997. Detection of telomerase activity in exfoliated cancer cells in colonic luminal washings and its related clinical implications. Br J Cancer 75: 548-553.

Yosry A 2006. Schistosomiasis and neoplasia. Contrib Microbiol 13: $81-100$.

Zamcheck N, Martin EW 1981. Sequential carcinoembryonic antigen levels in pancreatic cancer: some clinical correlations. Cancer 47: 1620-1627. 